\section{L.C. Coates and P.S. Helliwell reply}

To the Editor:

We thank Drs. Lubrano and Perrotta for their comments ${ }^{1}$ on our paper $^{2}$, and for the new data they provide from their clinic.

Our paper was written to explore disease activity states closer to remission than the published cutoffs for low disease activity ${ }^{3}$. Clearly it is harder for patients to meet MDA 7/7 than 5/7, and this corresponds to numerically lower values for the Psoriatic Arthritis Disease Activity Score and the Composite Psoriatic Disease Activity Index. However, it must be noted that patients are satisfied with the level of disease activity equivalent to 5/7 MDA, as noted in our paper, an important consideration in treating to target ${ }^{4}$. We agree that further studies are required in relation to radiographic damage progression and complete control of inflammation in patients with PsA. Regarding radiographic data, it is likely that the remission definition of the Disease Activity Index for Psoriatic Arthritis (DAPSA) will be equally relevant. However, we are reluctant to recommend the adoption of the definition of remission for the DAPSA because this measure does not cover all aspects of the disease: a patient may be in remission by the DAPSA criteria and still have active enthesitis and psoriasis ${ }^{5}$.

LAURA C. COATES, MB, BS, MRCP, PhD, UK National Institute for Health Research Clinical Lecturer, University of Leeds; PHILIP S. HELLIWELL, MA, DM, PhD, FRCP, Senior Lecturer in Rheumatology, University of Leeds,
Leeds, UK. Address correspondence to P.S. Helliwell, University of Leeds, Section of Musculoskeletal Disease, 2nd Floor, Chapel Allerton Hospital, Harehills Lane, Leeds LS7 4SA, UK.

E-mail: p.helliwell@leeds.ac.uk

\section{REFERENCES}

1. Lubrano E, Perrotta FM. Defining low disease activity states in psoriatic arthritis using novel composite disease instruments. J Rheumatol 2016;43:1765-6.

2. Coates LC, Helliwell PS. Defining low disease activity states in psoriatic arthritis using novel composite disease instruments. J Rheumatol 2016;43:371-5.

3. Helliwell PS, FitzGerald O, Fransen J. Composite disease activity and responder indices for psoriatic arthritis: a report from the GRAPPA 2013 meeting on development of cutoffs for both disease activity states and response. J Rheumatol 2014:41:1212-7.

4. Coates LC, Moverley AR, McParland L, Brown S, Navarro-Coy N, O'Dwyer J, et al. Effect of tight control of inflammation in early psoriatic arthritis (TICOPA): a UK multicentre, open-label, randomised controlled trial. Lancet 2015;386:2489-98.

5. Coates L, Helliwell P. Treating to target in psoriatic arthritis: how to implement in clinical practice. Ann Rheum Dis 2016;75:640-3.

J Rheumatol 2016;43:9; doi:10.3899/jrheum.160727 